\title{
Gestão estratégica: um estudo de caso de percepção de mudança de cultura organizacional
}

\author{
Francisco Antonio Coelho Junior
}

\begin{abstract}
Resumo
O presente trabalho objetiva analisar a influência da cultura de uma organização no processo de implementação de novo modelo de gestão, além de descrever as percepções dos empregados sobre transformações na cultura organizacional vigente, mostrando suas crenças e percepções compartilhadas acerca do processo de mudança. Foram realizadas quinze entrevistas semi-estruturadas em uma empresa pública da cidade de Juiz de Fora, Minas Gerais. Os resultados indicaram que crenças dos trabalhadores dificultam a efetiva implementação do planejamento estratégico. Fatores positivos e negativos foram apontados como entraves e/ou facilitadores do referido processo, propondo-se, ao final, iniciativas que promovam mudanças na cultura organizacional, culminando com a adoção da gestão estratégica.

Palavras-Chave: Gestão estratégica; Cultura organizacional; Mudança organizacional.
\end{abstract}

\section{Strategical management: a study of case of change's perception of organizational culture}

\begin{abstract}
The objective of this study was to analyze the influence of the organizational culture on the implementation process of a new management models, and also to describe the employees' perception about the organizational culture transformations, showing their beliefs and shared perceptions related to the changing process. Fifteen semistructured interviews were conducted in a public company of Juiz de Fora, in Minas Gerais State. Data showed that employees' beliefs block the effective implementation of the strategic planning. Positive and negative factors were pointed out as obstacles and/or facilities of the same process, and actions for promoting changes in the organizational culture were suggested and leading to the adoption of the strategic management.

Keywords: Strategic management; Organizational culture; Organizational change.
\end{abstract}

\section{Introdução}

O presente artigo visa discutir a presença e relevância do papel desempenhado pela cultura de uma organização interferindo no êxito ou fracasso de transformações na concepção, planejamento e redirecionamento organizacional. Visa, também, à compreensão de um contexto particular de um ambiente organizacional em mudança. Objetiva, ainda, descrever traços da cultura tradicional e suas modificações percebidas pelos empregados, em decorrência de transformações no modelo administrativo/gerencial, além de situar as crenças e percepções compartilhadas decorrentes do processo de mudança.

O conceito de cultura organizacional, segundo Tomei e Braustein (1993), consolidou-se em virtude da instituição da Teoria Contingencial da Administração, na década de 80. Freitas (1991), em estudos sobre clima e cultura organizacionais, ressalta que houve importantes incrementos nos estudos sobre cultura das organizações, criando-se uma multiplicidade de teorias e metodologias acerca do tema. Estudos que consideram aspectos da cultura organizacional nas organizações formais podem ser tidos como diferenciados entre si, em um âmbito geral, no que se refere à adoção do conceito de cultura, à metodologia utilizada e ao impacto desejado que tais estudos objetivam contemplar.

A cultura organizacional delineia o caráter de uma organização, não sendo imposta ou espontânea, mas sim um contínuo processo de enriquecimento, em virtude, principalmente, das interações sociais. Os significados apreendidos pelos sucessos e pelas falhas da organização, a linguagem utilizada, as definições de papéis e de hierarquias, metas, visões e objetivos organizacionais traçam e consolidam a cultura organizacional.

A cultura das organizações tenderá a se modificar caso novos membros sejam integrados ou

\footnotetext{
1 O autor agradece à professora Sônia Maria Guedes Gondim, da Universidade Federal da Bahia, pela orientação deste estudo. Endereço para Correspondência:
}

SQN 405, Bloco H, apto. 106 - Brasília-DF - 70846-080

E-mail: fercoepsi@yahoo.com.br acoelho@unb.br 
repelidos pelos grupos sociais, formal ou informalmente constituídos, de acordo com necessidades de adaptação interna ou externa da organização. A cultura de uma organização é dinâmica e mutável, podendo acontecer transformações culturais motivadas por diferentes agentes causadores (diretrizes governamentais, movimentos de greve trabalhista, inovações tecnológicas, variação do estilo gerencial, modificação dos processos de trabalho e insatisfação dos empregados da organização, por exemplo). Dessa forma, devemos analisar a perspectiva de cultura considerando-a em seu significado social e histórico, além da sua aplicação a organizações formais.

O conhecimento da cultura organizacional e de seus elementos constituintes fundamenta-se como pólo essencial para um melhor gerenciamento ou administração das organizações com alto grau de complexidade. Em particular, conhecendo-se o impacto cultural de desejadas mudanças estratégicas, poder-se-ia obter melhores instrumentos para a implementação de mudanças nas estruturas organizacionais como um todo.

Os empregados, uma vez que tenham assimilado e incorporado a cultura de uma organização, tendem a manter seu comportamento aprendido, balizando sua vivência organizacional em tal aprendizado. Transformações da cultura organizacional são, portanto, campos de difícil compreensão e previsão, extremamente árduos para o controle dos agentes de mudança. Vergara e Pinto (1998), em uma perspectiva qualitativa e quantitativa de investigação, estudaram o processo de mudança organizacional em uma organização específica, destacando a percepção compartilhada dos empregados sobre o processo de mudança, além do seu impacto na cultura vigente. Tal processo deve envolver um gerenciamento fiel e cônscio das dificuldades que, inevitavelmente, surgirão, sendo o planejamento, a organização, o controle e a avaliação indispensáveis ao sucesso dos programas desenvolvidos.

Adotamos a concepção de que, na ocorrência de mudanças e transformações no contexto organizacional, são afetados, de maneira direta, os objetivos e a estrutura de todo o sistema e, de maneira indireta, a cultura organizacional. Compreenderemos cultura organizacional à luz de perspectivas teóricas distintas, apresentadas a seguir.

De acordo com Freitas (1991), a cultura organizacional pode ser considerada um poderoso mecanismo controlador, que visa conformar condutas, visa homogeneizar o ambiente organizacional, de maneira que seja internalizada uma imagem positiva da organização, eliminando-se as diferenças e anulando a reflexão. Não obstante, a manipulação dos elementos que constituem a cultura organizacional pode ser considerada um importante meio de adequação das pessoas a um sistema cultural já consolidado e difundido por meio da homogeneização de idéias, crenças e atitudes (incorporam-se os valores da cultura organizacional, administram-se significados, há conformidade a regras). Tanto a adesão como a reprodução não demonstram a liberdade dos indivíduos em aceitar ou não determinado conteúdo, mas sim demonstram a eficiência e rigorosidade do controle cultural, em uma perspectiva ideológica de dominação. Saraiva (2002), em estudo realizado em várias organizações, analisou a percepção de empregados acerca da cultura organizacional vigente, discutindo o controle percebido pelos mesmos em organizações consideradas burocráticas, pouco flexíveis a adaptações e mudanças.

Segundo Morgan (1996), e na mesma linha de raciocínio de Freitas (1991), o significado, a compreensão e os sentidos compartilhados são diferentes maneiras de se descrever a cultura. Assim, a cultura da organização pode ser entendida como o processo de construção da realidade que permite às pessoas observar e compreender eventos, ações, objetos, expressões e situações particulares de maneiras distintas. Tal construção deve ser considerada um processo contínuo, proativo de construção da realidade, por meio do qual cada empregado representa e recria para si a sua realidade, inserido na organização (teia simbólica). A organização como um sistema de significados comuns compartilhados entre os empregados implica o reconhecimento das crenças e percepções de cada empregado sobre a organização. Dessa maneira, estrutura organizacional, regras, políticas, objetivos, metas, missões, descrições de cargos e procedimentos operacionais padronizados desempenham, semelhantemente, funções interpretativas em cada empregado, de acordo com suas percepções e julgamentos. Feverschutter (1997), em estudo de caso sobre a percepção compartilhada dos empregados sobre configurações de poder e cultura, discutiu perspectivas e estratégias de resistência, reação e adaptação, criadas por empregados, ante mudanças, de acordo com tais percepções vigentes acerca da relação cultura-poder.

Os elementos formais de uma organização incluem os sistemas organizacionais e seus produtores, produtos, serviços, recursos e administração, considerados como verdadeiros elementos do iceberg organizacional, ou seja, como os aspectos visíveis na dinâmica organizacional. Por outro lado, e abaixo da ponta visível do iceberg, também de forma vital, os elementos invisíveis da organização (organização informal) exercem sensíveis influências nos empregados. Tais elementos correspondem aos valores dos empregados, convicções e comportamentos em relação a si próprios e à organização. Em estudo sobre a percepção compartilhada por professores acerca de estilo de liderança em escolas públicas e particulares, 
Crespo e Andraus Junior (2000) discutiram um aspecto típico da cultura das organizações, a saber, estilo de liderança, nas suas dimensões simbólicas e de significados. A ênfase consistiu no estudo quantitativo do papel dos líderes estimulando, essencialmente, a criatividade dos seus subordinados. Tal estudo nos exemplifica a compreensão do fenômeno cultural liderança e sua percepção compartilhada.

Uma eficiente maneira de agruparmos os fatores visíveis e invisíveis da cultura de uma organização pode ser encontrada na definição de "rede de cultura" (Morgan, 1996). No centro da rede há os paradigmas organizacionais, ou seja, os modos estabelecidos até então para que a dinâmica organizacional fosse pautada. Tais paradigmas não se limitam a histórias, símbolos, rituais e rotinas, mas envolvem aspectos formais da organização, tais como o sistema de controle, as estruturas de poder e as estruturas organizacionais. Dessa maneira, para pensarmos em mudanças do paradigma organizacional, o agente ou facilitador da mudança deve atentar a alguns aspectos essenciais, tais como o planejamento do futuro almejado, desenvolvendo visões que propiciem a mudança (gerando compromissos com tais visões), propondo planos de ações para a concretização dessas visões (quem guia, como guia, o que necessita e onde as intervenções deverão acontecer), implementando as mudanças necessárias, assessorando e reforçando as mudanças e, finalmente, diagnosticando a situação atual, para posterior avaliação. Tais etapas correspondem ao processo de desenvolvimento organizacional almejado ao se propor mudanças na cultura da organização. Administrar essas mudanças implica administrar seus efeitos no paradigma institucional vigente e nas subculturas departamentais.

As subculturas de uma organização devem ser consideradas ricas em significação simbólica. Dessa maneira, e de acordo com Morgan (1996), as organizações podem ser consideradas minissociedades que têm os seus próprios padrões distintos de cultura e subcultura. Há, nas organizações, sistemas de valores distintos que interagem e competem entre si, criando diversificadas realidades organizacionais inseridas em uma cultura geral mais ampla, não uniforme. Dessa maneira, contradições entre subculturas organizacionais podem ser visíveis e identificáveis, de modo que cada sistema cultural deve ser compreendido referenciandose às suas especificidades.

Nesse contexto de diferenças e especificidades, o processo de reeducação é concebido como uma inevitável decorrência do processo de mudança de cultura ou, em outras palavras, como uma tarefa de aculturação, promovendo mudanças de conhecimento e crenças, mudança de valores e padrões, mudança nas ligações e necessidades emocionais, além de mudanças de conduta e percepção, que influenciarão a execução posterior das atividades de cada empregado. $\mathrm{O}$ aspecto central, voltado à implementação do pensamento estratégico nas organizações, refere-se ao impacto das transformações culturais que tal pensamento imporá aos valores culturais atuais, e por isso faz-se necessário o acompanhamento reeducativo dos empregados em direção à cultura desejada.

\section{Gestão e Planejamento Estratégico}

A gestão estratégica pode ser definida como um sistema de indicadores de desempenho que delineia os caminhos a ser desenvolvidos pela administração quantos às iniciativas e ações estratégicas previamente definidas. O pilar da gestão estratégica encontra-se, não no trabalho realizado em departamentos isolados, mas sim por processos, tornando as atividades organizacionais integradas, sistêmicas e interdependentes.

O planejamento estratégico, especificamente na organização de estudo, fora denominado Modelo de Gestão Estratégica. Nas organizações orientadas por processos, a estrutura organizacional tende a ser menos vertical e mais horizontal. $\mathrm{O}$ trabalho se organiza em torno dos processos e das equipes que o executam. $\mathrm{O}$ controle é assumido pela pessoa que executa o processo. Os gerentes se aproximam mais dos clientes e dos executantes do trabalho. Cada membro de uma equipe terá, pelo menos, uma familiaridade básica com todas as etapas do processo e realizará uma variedade de tarefas. Ressaltamos que nem todos os membros da equipe realizam exatamente o mesmo trabalho, pois cada empregado possui específicas competências e qualificações.

Tal modelo configura-se em temas estratégicos amplos, direcionados a objetivos estratégicos específicos. Em outras palavras, cada tema estratégico é subdivido em processos, e estes representam o menor conjunto de atividades e ações estratégicas que necessitam ser executadas em determinado período de tempo e velocidade. Para facilitar a compreensão, pensemos no tema estratégico comunicação. Há objetivos estratégicos específicos delimitados para comunicação (como melhorar a comunicação interna, ou a comunicação com o cliente externo, por exemplo). Cada objetivo estratégico será constituído por processos, tais como melhoria dos meios de comunicação, padronização de atendimento ao cliente, uniformização do uso dos recursos eletrônicos, enfim, processos contidos no objetivo estratégico comunicação. Dessa maneira, em ordem decrescente, há a definição de temas estratégicos mais amplos, posteriormente os objetivos estratégicos e, finalmente, a delimitação dos processos estratégicos.

Com a adoção da gestão estratégica, a empresa deveria criar e adaptar uma cultura de transição em relação à cultura organizacional vigente. Tal necessidade de adaptação da cultura da organização de estudo fora 
desencadeada por mudanças no mercado externo, que ocasionaram um redirecionamento da empresa, culminando na criação do Modelo de gestão estratégica, balizado no Balanced Scorecard, proposto por Kaplan e Norton (1994).

A base metodológica do Modelo de gestão estratégica, o Balanced Scorecard, é definida como um sistema de medição de desempenho utilizado para comunicar e gerenciar a estratégia das organizações. Visa mensurar indicadores relacionados ao ambiente $\mathrm{e}$ desempenho organizacional, relacionando medidas de resultado (indicadores de fato, ocorrências) e vetores de desempenho (indicadores de tendências) em torno de quatro perspectivas distintas e complementares entre si, a saber, Financeira, Cliente, Interna e Aprendizado e Inovação. O Scorecard induz ao raciocínio sistêmico dinâmico, integrando a organização em um todo complexo e interdependente.

O Scorecard é um sistema de gestão estratégica utilizado para a definição de importantes processos gerenciais, tais como estabelecimento de metas individuais e de equipe, remuneração, alocação de recursos, planejamento e orçamento, feedback e aprendizado estratégico. Tal sistema de gestão fornece aos gerentes indicadores sobre significativos aspectos do ambiente e desempenho organizacional, possibilitando que se mantenham os rumos da excelência organizacional.

Em aspectos gerais, a adoção do Scorecard objetiva processos gerenciais críticos (indicadores críticos ou fatores-chave de sucesso), além de traduzir a visão e a estratégia organizacional (definir objetivos estratégicos específicos e identificar vetores críticos que determinam tais objetivos estratégicos), comunicar e associar objetivos e medidas estratégicas, planejar, estabelecer metas e alinhar iniciativas estratégicas, além de aperfeiçoar o feedback e o aprendizado estratégico. Nessa perspectiva sistêmica, há um enriquecimento organizacional por meio do Modelo Learning Organization, desenvolvido por Senge (1990), descrito a seguir.

\section{As empresas como Organização de Aprendizagem (Learning Organization)}

De acordo com Senge (1990), as organizações de aprendizagem constituem-se na expansão contínua das pessoas quanto à sua capacidade de criar resultados e valorizar processos, dos quais emergem novos e elevados padrões de raciocínio. A aspiração coletiva é reforçada e as pessoas aprendem continuamente a aprender em grupo. Valoriza-se, dessa maneira, o pensamento sistêmico em detrimento de uma visão individualizada do todo.

O aprendizado em grupo será vital para as organizações, pois a unidade fundamental de aprendizagem nas organizações modernas é o grupo, não os indivíduos. $O$ fato é que as organizações somente terão capacidade de aprender se os grupos forem capazes de aprender. Para tal, é necessária uma mudança de mentalidade das pessoas acerca da importância de os trabalhos serem desenvolvidos em equipes, agregando valor aos processos organizacionais. Senge (1990) concebeu cinco tipos de disciplinas, a saber, domínio pessoal, modelos mentais, objetivo comum, aprendizado em grupo e raciocínio sistêmico.

Dominio pessoal. Busca esclarecer os elementos que são realmente importantes para cada pessoa, levando-as a viver de acordo com suas aspirações. A essência do domínio pessoal está em aprender a gerar e manter tensão criativa, resultante da justaposição dos objetivos pessoais - o que desejamos - com uma imagem clara da organização em nossas vidas. A tensão criativa visa unificar tais visões, e resulta do empenho para a solução de conflitos.

Modelos mentais. São as idéias arraigadas, as generalizações, ou mesmo imagens que determinam nossos comportamentos e atitudes diante do mundo. $\mathrm{Na}$ maioria das vezes, novas idéias deixam de ser aplicadas por ser conflitantes com imagens internas profundamente arraigadas de como o mundo funciona, que nos limitam a maneiras habituais de pensar e agir. Os modelos mentais são ativos, pois estruturam nosso modo de agir, modelando também nossos comportamentos e percepções.

Objetivo comum. Dificilmente pensamos em uma organização sem objetivos comuns, valores ou compromissos compartilhados entre seus membros. As pessoas tendem a formar uma identidade organizacional comum, de acordo com a missão da empresa, proporcionando, assim, coerência às atividades e tarefas.

Aprendizado em grupo. Quando as equipes estão realmente aprendendo, além de produzir resultados em conjunto, seus integrantes também se desenvolvem, individualmente, com rapidez. $\mathrm{O}$ aprendizado em grupo começa com o diálogo, com a prática e, principalmente, com o raciocínio em grupo.

Raciocinio sistêmico. São elementos interligados em um mesmo sistema. Cada elemento influencia o outro, geralmente por ações inter-relacionadas.

Assim, considera-se o raciocínio sistêmico a quinta disciplina, pois é a disciplina que engloba as outras quatro, fundindo-as em um conjunto coerente de teoria e prática. Reforçando cada uma das disciplinas, o raciocínio sistêmico estará sempre comprovando que o todo pode ser maior que a soma das partes. Ressaltamos que os indivíduos não sacrificam seus interesses pessoais pelo objetivo comum, de acordo com Senge (1990), pois esse objetivo se torna uma extensão dos seus objetivos pessoais. 
De acordo com Senge (1990), a maneira como as organizações são estruturadas e administradas, como os cargos são definidos e como os empregados foram ensinados a raciocinar e interagir provoca carências de aprendizagem individual nas organizações. As organizações de aprendizagem investem na reflexão, aprendizagem grupal e na capacidade de desenvolver objetivos comuns e análises em conjunto de problemas complexos. A organização é compreendida, dessa maneira, como um sistema que não funciona independente da coesão das suas partes constituintes.

\section{Método}

\section{Participantes}

A seleção dos participantes foi realizada por critério intencional ou proposital, de acordo com AlvesMazzotti e Gewandsnadjer (1998). Considerou-se, para a escolha dos participantes, a afinidade dos mesmos ao tema estudado e aos objetivos desta pesquisa.

A empresa, pública, de administração indireta, pertence ao ramo de pesquisas agropecuárias. Foram realizadas 15 (quinze) entrevistas com gerentes de objetivos estratégicos, empregados recém-contratados e empregados com mais tempo de empresa.

Quanto ao sexo, onze homens e quatro mulheres foram entrevistados. No que se refere à idade, houve a prevalência de um perfil adulto/idoso nas pessoas entrevistadas. Destas, duas tinham de entre $30 \mathrm{e}$ 40 anos, sete estavam na faixa de 41 a 50 anos, cinco possuíam a idade entre 51 e 60 anos, e um entrevistado tinha mais de 60 anos de idade.

Três entrevistados se situavam na faixa de até 10 anos de trabalho na empresa. Um estava na faixa de 11 a 20 anos e onze empregados entrevistados estavam na faixa de 20 a 30 anos de empresa, demonstrando a prevalência de pessoas mais antigas na organização.

\section{Instrumentos/procedimentos}

Utilizou-se um questionário qualitativo, previamente elaborado, fundamentado na técnica da entrevista semi-estruturada. Continha vinte e duas questões abertas, que versavam sobre a identificação dos participantes, crenças e percepções acerca do trabalho e do cotidiano na empresa, percepção de mudanças organizacionais com a introdução do modelo de gestão estratégica e avaliação do mesmo, percepção do desenvolvimento de carreira e aspectos afetivoemocionais relacionados ao trabalho. No geral, cada entrevista teve uma duração média de quarenta minutos, dependendo do rapport estabelecido entre pesquisador e entrevistado. Todas foram gravadas, com o consentimento prévio de cada entrevistado, para posterior transcrição e análise de conteúdo.

\section{Análise dos resultados}

A interpretação dos relatos fundamentou-se em técnicas de análise de conteúdo, em especial as análises temática e categorial propostas por Bardin (1977). A análise temática visa à análise e interpretação dos conteúdos manifestos comuns na comunicação, ao passo que a análise categorial é um artifício de ordenamento de todo o material coletado em um conjunto de unidades de registro significativas (argumentos básicos e centrais), de forma que se busque uma unidade interna entre as categorias e uma pertinência com o material de análise posterior.

\section{Resultados}

\section{Percep̧̧ão da cultura da empresa}

A missão e os objetivos da empresa parecem estar claros e definidos para os empregados. São formalizados e comunicados publicamente a seus membros. Os trabalhadores consideram que a estrutura da empresa é claramente definida, utilizando como base o organograma formal, com o trabalho dividido em tarefas distintas e coordenadas entre si. Os elementos que compõem a estrutura organizacional da empresa possibilitam alcançar uma congruência interna ou harmônica, permitindo que haja uma coordenação entre as tarefas e os ajustamentos necessários.

Há um processo de supervisão direta que, de acordo com Mintzberg (1995), possibilita a coordenação por meio de uma pessoa que tem a responsabilidade pelo trabalho dos outros, dando as instruções necessárias e monitorando as suas ações. Notamos, entretanto, que a divisão por tarefas individuais acabou por se tornar o mecanismo executor das atividades de cada trabalhador, tendo, por conseqüência, consolidado tal individualismo como a típica maneira de se executar os afazeres. $\mathrm{O}$ respeito à estrutura hierárquica contribuiu para a pouca participação dos empregados no todo organizacional. Outra justificativa apontada pelo centralismo e controle que perpassam a estrutura administrativa da empresa se concentra na época da sua regimentação, ocorrida no regime militar.

A estrutura administrativa da empresa reforça a presença de um manejo gerencial autoritário, coercitivo, com dificuldades para se valorizar a criatividade e iniciativa dos empregados. Na empresa, a organização do trabalho encontra-se distribuída de tal forma que cada setor possa funcionar independente do outro, como se fossem engrenagens de uma máquina, de acordo com Morgan (1996). Dessa forma, há uma minuciosa divisão do trabalho, estruturada por ciclos de atividades que se repetem invariavelmente. Há padronização dos métodos, procedimentos, deveres e responsabilidades estabelecidos a priori. Com a 
implementação da gestão estratégica, busca-se criar alicerces para que tal visão individualista seja transformada em uma visão compartilhada acerca dos processos organizacionais, compreendendo-se que cada etapa do trabalho pertence a um contexto mais amplo e está inserida em uma perspectiva de aprendizagem contínua.

Em relação à política de investimentos em treinamento e desenvolvimento, valoriza-se a atividadefim em detrimento à atividade-meio, o que gera insatisfação por parte dos empregados ligados a esta última. A capacitação contínua dos empregados possibilita que se agregue valor ao trabalho. Tal perspectiva de valorização, mesmo que timidamente, já nos permite vislumbrar a influência da gestão estratégica nas relações de trabalho.

Outro traço típico da empresa refere-se à ênfase nas regras e procedimentos formalizados por escrito, utilizados para determinar o comportamento das pessoas de maneira prévia, definitiva e estável. O comportamento dos empregados se torna regulamentado, ocasionando a especialização do trabalho (as organizações formalizam o comportamento para reduzir sua variância, com a finalidade de predizer e controlar). Identifica-se, dessa maneira, a subcultura de estruturação e planejamento, com normas explícitas, minimamente definidas, com a clareza do papel que desempenham e o planejamento do trabalho voltado para o cumprimento de tais normas. Ressaltamos que a fidelidade às normas e regras tem como conseqüência a percepção de que a empresa está imersa em burocracias e regras rígidas. Dessa maneira, despende-se tempo e rechaça-se a criatividade dos empregados, já que os processos são fechados e deterministas.

Um dos aspectos mais marcantes da cultura organizacional estudada refere-se à responsabilidade dos empregados no cumprimento das metas e objetivos organizacionais, gerando um comprometimento muito intenso com a organização. São comuns sentimentos de identificação com a empresa, de forma que alguns empregados concebem-na, metaforicamente, como uma segunda mãe ou segunda família. Tal comprometimento pode ser vislumbrado no esforço pessoal pela melhoria de desempenho e dedicação ao trabalho.

O ambiente estável e o grau de certeza de haver poucas mudanças na rotina de trabalho contribui para que haja a permanência dos empregados na empresa. Há, também, um orgulho muito intenso em se trabalhar na empresa, havendo, inclusive, dificuldades no desligamento (aposentadoria) dos empregados. Os empregados concebem seu trabalho como parte integrante da sua identidade, representando, além de fonte de sustento pessoal, um complemento vital no processo de subjetivação. $\mathrm{O}$ tempo de serviço pode ser um elemento que favoreça ou dificulte a adoção da gestão estratégica, na medida em que os empregados com mais tempo de casa podem colaborar ou tornar árduo (resistência ao novo) o processo de implementação de tal modelo.

O status na empresa pode ser concebido por vias distintas, a saber, a formação acadêmica do empregado, variável; o individualismo que caracteriza cada função; a dificuldade de relacionamento interpessoal, referendando ao individualismo que caracteriza a execução do trabalho; a tradição do nome da empresa na sociedade brasileira e mundial; e o status produzido pelo reconhecimento do esforço do empregado. O abrandamento do status provocado pela titularidade do empregado demandará muito esforço por parte dos empreendedores da gestão estratégica. Tal status não produz nada de proveitoso para a organização e, ao contrário, gera animosidade entre os empregados.

A imagem de perseverança e confiança na empresa representa orgulho para os empregados, novamente remetendo ao reconhecimento externo da empresa, cuja principal característica, nesse sentido, refere-se à credibilidade de suas pesquisas. Tal credibilidade encontra respaldo na sua história e no progresso de suas descobertas científicas propostos na sua missão e objetivos organizacionais.

Tradicionalmente, a função dos recursos humanos encontra-se atrelada à rotina, ao cumprimento de burocracias formalizadas, ao controle e preenchimento de documentos e à divisão/sistematização de funções. Com a efetiva implementação do modelo de gestão estratégica, tal concepção de recursos humanos tende a se alterar, alcançando-se um ponto ótimo entre as tradicionais atividades características de um departamento pessoal e entre a nova concepção de recursos humanos que visamos implementar. Ressaltamos que a nova perspectiva desejada para os recursos humanos (proativo ao desenvolvimento de pessoal) ainda se encontra em fase embrionária, em um contínuo processo de construção.

A identificação do servidor público como uma pessoa paralisada, sem qualquer motivação para a realização de seus afazeres, torna-se perceptível para os próprios empregados, pois parece existir uma crença compartilhada que contempla tal percepção de acomodação (subcultura de acomodação). Essa constatação dificulta, inclusive, a adoção de novas perspectivas de enriquecimento do próprio cargo. Outra subcultura identificada na empresa refere-se à insatisfação com o serviço público. Ela pertence à denominada cultura do servidor público, de acomodação e de desinteresse pelo seu trabalho. A contribuição da própria empresa em não pressionar ou exigir mais de seus empregados favorece à adequação dos empregados ao ritmo da 
organização. A dificuldade em se relacionar com o novo caracteriza o ambiente organizacional da empresa de estudo. Atitudes inovadoras tendem a ser observadas com desconfiança, o que faz com que as pessoas que queiram ser inovadoras sejam vistas como desadaptadas à cultura vigente.

Lemas e dizeres estão fortemente arraigados na cultura da empresa, e são utilizados para a diferenciação daqueles que cumprem suas tarefas e demandas organizacionais (vestem a camisa e empurram o piano), em relação àqueles que não se envolvem, efetivamente, com a empresa (não vestem a camisa e sentam no piano). A comunicação é vertical, obedecendo a posições hierárquicas formalmente definidas, de acordo com o organograma. Será de grande valia para o planejamento estratégico, já que a comunicação é estratégica em qualquer segmento do mercado ou ramo de atividade. Há falhas na atual concepção de comunicação na organização de estudo, embora a gestão estratégica almeje a melhoria do seu processo e gerenciamento. Um dos objetivos estratégicos contemplará exclusivamente a comunicação, interna e externa, valorizando, inclusive, o contato com o cliente externo.

\section{Crenças e percepções sobre a gestão estratégica}

Poucas características culturais da empresa alteraram-se em virtude da implementação da gestão estratégica. Na realidade, a gestão estratégica encontrase em fase embrionária, de maneira que sua fundamentação, sistematização e seu aperfeiçoamento ainda acontecem paralelos ao processo de sua implementação. Embora haja perspectivas promissoras para a implementação do novo modelo de gestão, não houve, até o momento, transformações reais voltadas à adoção dos conceitos e fundamentos que balizam tal modelo. Apesar da crença compartilhada sobre a eficácia do modelo, o pouco comprometimento dos empregados e chefias no processo, além da ausência de programas de treinamentos específicos e falhas na comunicação, parecem ser as razões principais para a não-efetivação do novo sistema de gestão.

Há fatores significativos de dificuldade, observados no processo de implementação do modelo de gestão estratégica, que se relacionam ao próprio desempenho da empresa no processo. Em outras palavras, mesmo sem intenção explícita ou proposital, parece haver obstáculos impostos ao modelo pela própria empresa, refletindo na maior ou menor absorção do processo por parte dos empregados como um todo.

O processo de mudança da cultura da empresa tem tido uma importância secundária por parte dos responsáveis pela implementação do modelo, e vem, por isso, sendo pouco compreendido. Caso houvesse um real entendimento acerca do impacto de tais mudanças propostas nos âmbitos pessoal e organizacional, a resistência ao modelo, por parte dos empregados, poderia ser minimizada ou mesmo diluída. O pouco envolvimento dos gerentes de objetivos estratégicos no processo e a carência de treinamentos específicos novamente surgem como elementos nocivos e comprometedores ao sucesso do modelo.

Se há pouco envolvimento dos gerentes de objetivos estratégicos, por conseqüência há, também, pouco envolvimento dos empregados em geral, pois cabe a tais gerentes a divulgação e internalização do modelo em toda a empresa, nas respectivas áreas e departamentos. A rotina incessante de trabalho também colabora para dificultar a implementação do modelo, pois, diferente de sua proposta, ele é compreendido pelos empregados como um fardo a mais, como mais uma atividade a ser desempenhada no ambiente de trabalho, e que acaba por dificultar a execução natural das atividades de rotina. Ressaltamos que, em razão da carência de empregados em alguns setores da empresa, há um acúmulo de tarefas para os outros, o que dificulta a participação dos mesmos em programas de capacitação e desenvolvimento. A eficácia dos treinamentos também pode ser questionada quando se constata que o básico para o trabalho não foi realizado, que é justamente ouvir os empregados quando da elaboração e criação do modelo, para saber de suas crenças, medos e sugestões acerca do mesmo.

Uma outra razão apontada para o baixo envolvimento dos empregados no processo refere-se ao tempo de trabalho na empresa. Como são empregados cuja média de tempo de serviço oscila entre vinte e vinte e cinco anos, a cultura já está arraigada neles, havendo resistência e receio ao novo. Dessa maneira, notamos que tem sido dada pouca atenção e importância à cultura vigente. Acreditamos ser necessário, antes de quaisquer implementações efetivas, atentar à cultura vigente, identificando os pontos frágeis e os pontos de apoio que devem estar interferindo na adoção do modelo, valorizando o empregado, em uma perspectiva preconizada pelo novo sistema de gestão.

A falha de comunicação e de divulgação maciça na empresa sobre a gestão estratégica é outra questão a ser considerada, caso haja um real interesse na implementação do modelo. Lidar com as expectativas dos empregados e gerenciar melhor o processo de treinamento também parecem ser medidas cabíveis para o modelo.

\section{Raciocínio Estratégico}

Trabalhar estrategicamente é o objetivo final do modelo de gestão estratégica. Esse aspecto já começa a ser vislumbrado, mesmo que timidamente, na empresa, referindo-se à visão estratégica que algumas pessoas, mais diretamente relacionadas ao modelo, passaram a 
desenvolver. Pensam estrategicamente, passam a perceber a importância dos processos e, ainda, passam a se perceber como membros participantes de tais processos. Compreenderam que a empresa não mais era um sistema forte e seguro, mas que necessitava modernizar-se de acordo com as tendências do mercado.

Há, em setores isolados da empresa, iniciativas tomadas por líderes de processos estratégicos que começam a vislumbrar a perspectiva de trabalho em equipe. Tais setores, com subculturas próprias, já constataram dificuldades básicas ao se adotar o modelo, por ele não estar pronto, devidamente definido e padronizado, havendo um desconhecimento compartilhado acerca do processo. Outro entrave refere-se à não-quantificação dos resultados, de maneira que não há uma realimentação segura, não se mensuram nem se avaliam, seguramente, as transformações ocorridas até o momento.

Ressaltamos, ainda, na perspectiva de subculturas, que alguns setores já trabalham em equipe. Realizar trabalhos em equipe não é tão-somente dividir as tarefas para todo o grupo e cada um faz a sua parte em nome do todo. Trabalhar em equipe implica a pessoa ser capaz de desempenhar todas as funções que forem destinadas à equipe e ela saber o porquê de estar fazendo aquilo, sentindo-se parte do processo.

Na perspectiva da gestão estratégica, até mesmo o sistema de avaliação tenderá a ser por equipes, não mais individual, o que facilitará a execução dos trabalhos em processos e em grupo. Por outro lado, há conflitos iminentes na adoção da avaliação de desempenho por equipes. Como comprometer em equipes empregados que, acostumados a executar suas tarefas individualmente, também eram premiados individualmente? Em outras palavras, como gerar comprometimento em nome de uma equipe, com a premiação de desempenho sendo revertida para a equipe, desconsiderando os esforços individuais isolados? Além disso, será que aqueles que se destacariam mais nos grupos não se sentiriam desmotivados e desprestigiados, em virtude da minimização dos seus esforços individuais? Essas indagações se tornam relevantes quando avaliamos a dificuldade em conciliarmos a autonomia do empregado com a adoção de políticas de comunidades coletivistas.

A dinâmica da empresa ainda apresenta traços da sua cultura tradicional. Não houve uma reestruturação do organograma formal, e ainda há uma relação hierárquica cristalizada entre superior/subordinado. Novos valores, competências profissionais e estilos de liderança ainda são típicos de determinados setores da empresa. Não é algo já estabelecido, mas em processo de desconstrução e reconstrução, observado nas tentativas de melhorias dos processos identificados.

Um aspecto essencial que necessita ser trabalhado para a adoção do modelo refere-se à confiança mútua que precisará ser desenvolvida com o trabalho em equipe. Em virtude da sua estrutura de trabalho individualista, as relações humanas na empresa se cristalizaram. Como a perspectiva de trabalho em equipe implica, necessariamente, um contato maior com o outro, haverá dificuldades no relacionamento e confiança entre as pessoas, já que o contato com o outro, até então, era desnecessário à execução das atividades. Tal demanda precisa ser constatada, pois será um dos pontos nodais para o desenvolvimento da gestão estratégica.

Há a crença compartilhada de que tal modelo será inovador e transformador para a empresa, considerando-se que toda a dinâmica organizacional será receptiva ao mesmo. $O$ essencial que os empregados da empresa têm que compreender é que o desenvolvimento organizacional, de acordo com Miranda (1985), será uma resposta à mudança proposta e resultará de uma complexa estratégia educacional, que tem por finalidade transformar as crenças, as atitudes, os valores e a estrutura da organização de modo que elas possam adaptar-se melhor aos novos mercados, às novas tecnologias, aos novos desafios e ao próprio ritmo lento e progressivo do processo de mudança.

\section{Algumas Conclusões}

Uma conclusão clara refere-se à imaturidade e à timidez do processo de gestão estratégica na empresa. Em outras palavras, o modelo de gestão estratégica ainda é considerado regra para a maioria dos empregados da empresa, de maneira que somente aqueles envolvidos no modelo têm uma noção mais clara do que seja, efetivamente, trabalhar em equipes em uma organização de aprendizagem. Ressaltamos que o desconhecimento da gestão estratégica e o conseqüente despreparo de alguns dirigentes em lidar com a mesma podem estar dificultando a sua implementação, já que a gestão estratégica ainda não conseguiu encontrar um norte a seguir e a se efetivar.

No que tange à cultura organizacional vigente, constatamos a valorização das habilidades no desempenho de tarefas individualizadas, previamente estabelecidas para cada empregado, além da exaltação da honra de se pertencer à empresa e também da obediência/dedicação fiel dos seus empregados. Por outro lado, tais empregados desejam segurança, respeito e dignidade, buscando sua satisfação pessoal/profissional no trabalho. A organização de estudo é uma extensão da vida particular dos seus atores, pois os empregados são envolvidos e comprometidos de tal maneira que a empresa passa a ser essencial na formação da identidade dos mesmos.

As comunicações são centralizadas e exige-se obediência a regras e padrões formais da empresa 
(burocracias). Há um status que permeia as relações interpessoais. Ressalta-se que a cultura estabelecida é muito forte, bastante arraigada nos seus empregados e sustentada por eles. Há uma tendência em abolir o novo, gerando-se atitudes negativas por parte dos empregados quando há uma mudança de propostas paralela à habitual maneira de se desenvolver as relações de trabalho.

O modelo de gestão estratégica precisa ser melhor delimitado quanto às suas propostas e quanto à área de abrangência das mesmas. Há pouca mensuração e controle dos resultados obtidos até agora com a gestão estratégica. Ressaltamos que ela implicará alterações marcantes na cultura vigente, pois é sabido que a cultura de uma empresa demora a tomar forma e a se desenvolver. Além disso, ela cria e mantém uma ordem, logo, mudá-la é um processo lento, difícil e nem sempre bem-sucedido.

Transformações significativas na cultura da organização de estudo não foram constatadas, o que seria conseqüência natural em decorrência da implementação da gestão estratégica. Uma das conclusões plausíveis para tal fato refere-se, justamente, à pouca atenção que tem sido direcionada à cultura atual da empresa, que é um fator potente de impedimento a novas perspectivas de gestão. Em outras palavras, há uma cultura inadaptável, que se caracteriza por pessoas pouco propensas à mudança e por uma centralização burocrática intensa. Nessa cultura, as chefias tendem a ignorar mudanças contextuais relevantes e a prender-se a estratégias estabelecidas e práticas arraigadas. Dificulta para todos, em especial àqueles que estão na parte inferior da hierarquia, a implementação de novas estratégias e práticas na organização.

Importantes mudanças culturais não acontecem com facilidade nem rapidez, em especial nas grandes organizações. Os responsáveis pelas mudanças de cultura devem desenvolver um know-how necessário para que sejam evitados traumas gerados por elas. Tais responsáveis devem atuar na tensão criativa dos empregados, que implica os ideais, propósitos fundamentais, valores e objetivos voltados à definição da direção e metas a serem atingidas. A participação efetiva dos empregados no processo de planejamento estratégico deverá ser concebida como vital para o seu sucesso. A gestão estratégica deverá ser absorvida por todos, delimitando a execução das ações, tarefas e atribuições, nos âmbitos intra e extra-organizacionais, incorporando-se novos elementos à cultura vigente.

\section{Referências}

Alves-Mazzoti, A. J. \& Gewandsnadjer, F. (1998). O método nas ciências naturais e sociais: Pesquisa Quantitativa e Qualitativa. São Paulo, SP: Pioneira.

Bardin, L. (1977). Análise de Conteúdo. Lisboa: Edições 70.

Crespo, M. L. F. \& Andraus Junior, S. (2000). Diagnóstico e comparação entre os estilos de liderança criativa exercida por diretores de escolas públicas e particulares. Psico-USF, 5(2), 55-65.

Feverschutter, S. G. (1997). Cultura organizacional e dependências de poder: a mudança estrutural em organização do ramo de informática. Revista de Administração Contemporânea, 2(1), 73-96.

Freitas, M. E. de. (1991). Cultura organizacional: formação, tipologias e impacto. São Paulo, SP: Makron, McGraw Hill.

Kaplan, R. S. \& Norton, D. P. (1994). A estratégia em ação. Rio de Janeiro, RJ: Campus.

Mintzberg, H. (1995). Criando organizacooes eficazes estruturas em cinco configurações. São Paulo, SP: Atlas.

Miranda, G. I. (1985). Organização e métodos. 6. ed. São Paulo, SP: Atlas.

Morgan, G. (1996). Imagens da organiżação. São Paulo, SP: Atlas.

Saraiva, L. A. da S. (2002). Cultura organizacional em ambiente burocrático. Revista de Administração Contemporânea, 6(1), 187-207.

Senge, P. (1990). A quinta disciplina. Arte, teoria e prática da organização de aprendizagem. 6. ed. São Paulo, SP: Nova Cultural.

Tomei, P. A. \& Braustein, M. L. (1993). Cultura organizacional e privatização. A dimensão humana. São Paulo: Makron Books.

Vergara, S. C. \& Pinto, M. C. S. (1998). Cultura e mudança organizacional: o caso TELERJ. Revista de Administração Contemporânea, 2(2), 63-84.

Enviado em marco de 2003

Reformulado em junho de 2003 Aprovado em junbo de 2003

Sobre o autor:

Francisco Antonio Coelho Junior é bacharel e psicólogo, mestrando em Psicologia Social e Organizacional pela Universidade de Brasília e bolsista da CAPES. 
